\title{
Affect of adhesion and properties of kenaf (Hibiscus cannabinus L.) stem in particleboard performance
}

\begin{abstract}
The objective of this work was to evaluate the adhesion and basic properties of kenaf stem, and its physical and mechanical properties on particleboard panels. In this study, rubberwood (RW) was used as a control. Single-layer experimental panels were produced from whole stem, core, and bast particles of kenaf. Findings revealed that the core part resulted in higher wettability and lower contact angle than the bast. Kenaf bast (KB) gave the highest buffering capacity, while kenaf core (KC) gave the lowest buffering capacity towards acid. The lowest specific gravity was shown by KC followed by kenaf whole stem (KWS) and KB. For particle analysis, KWS gave the highest acceptable particle distribution (73.9\%), whilst KC, $\mathrm{KB}$, and RW had particle distributions of $62.5,68.1$, and $56.8 \%$, respectively. Particleboard panels produced from KWS had the highest average values of modulus of rupture and modulus of elasticity with good compaction under scanning electron microscopic. Panels made from bast particles had the lowest mechanical properties among the three types of panels. The internal bonding strengths and dimensional stability of the specimens followed the similar trend above. The results of this study indicate that the specific gravity and adhesion properties of the starting material play a role in determining the physical and mechanical properties of the particleboard panels.
\end{abstract}

Keyword: Adhesion; Contact angle; Wettability; Buffering capacity; Kenaf 